\title{
Estimation of the In-Cylinder Pressure in Diesel Engines-Synchronous Generators Sets
}

\author{
J. Ch. Dermentzoglou* and Konstantinos Smyrloglou \\ Statutory Laboratory P.ELE.D.EM, Department of Physics, International Hellenic University, 65404, St Lucas Campus, Kavala, \\ Greece
}

Received 3 February 2020; Accepted 4 August 2020

\begin{abstract}
This paper deals with the estimation of cylinder pressure of a four-stroke diesel engine which drives a synchronous generator, by applying two methods. The first method is based on the utilization of the current and speed developed by the synchronous generator of the power production system along with the utilization of a mathematical model which considers the dynamic model of the crankshaft. The second method is based on system identification techniques and the development of ARMAX models based on available pressure and acceleration raw data, of an identical diesel engine. This model is applied to acceleration data obtained during the operation of the investigated diesel engine, in order to estimate in-cylinder pressure. Finally, the relevant results of the two methods are compared demonstrating the similarities and differences due to the different approach.
\end{abstract}

Keywords: Internal Combustion Engine, Condition Monitoring, In-Cylinder Pressure, Vibration Signals, System Identification Techniques, crankshaft dynamic model.

\section{Introduction}

Cylinder pressure is one of the most important signals used for control and condition monitoring purposes of the internal combustion engines. Traditionally, the cylinder pressure is measured by installing pressure sensors inside the combustion chamber of a cylinder Hubbard $\mathrm{M}$ et al [1], Morris J and LiChi [2], Winter $\mathrm{H}$ et al [3], Chandroth G. O. et al [4], d'Ambrosio S. [5]. This is an "intrusive" and cost demanding technique due to the modification required to the cylinder head. Moreover, the pressure sensors undergo high thermal strain and thus their operational life is limited. Therefore, a lot of useful work has be done in order to develop indirect methods of pressure estimation, Brown TS and Neill WS [6], P. F. Maria et al [7], Citron SJ et al [8], Schagerberg S and McKelvey [9], Taglialatela F et al [10], Al-Durra A. et al [11], Syed Abbas Ali and Samir Saraswati [12], Jairo A. Grajales et al [13], Li Zhixiong et al [14].

P.F. Maria et al [7], introduce a mathematical model for the combustion process in order to estimate the in-cylinder pressure of a diesel engine. Citron SJ et al [8], Schagerberg S and McKelvey [9], Taglialatela F et al [10], Al-Durra A. et al [11], Syed Abbas Ali and Samir Saraswati [12], propose various mathematical models for in-cylinder pressure estimation by utilizing engine speed fluctuations or angular position. Citron SJ et al [8], use an elastic model of the engine-drivetrain system and as its input the measured fluctuating speed, in order to determine total engine torque and engine pressure torque. Then, the resultant engine pressure torque waveform is used to extract the cylinder pressure waveform. Schagerberg S and McKelvey [9], have developed a mathematical model in order to relate the pressure of each cylinder of a multi-cylinder engine to the resulting torque of the crankshaft. Raw data from torque and cylinder pressure sensors have demonstrated the effectiveness of the proposed model. Taglialatela $\mathrm{F}$ et al [10], introduce a Multi-Layer Perceptron neural network to relate engine speed and the pressure peak of a cylinder with its angular location, in order to evaluate in real-time, the combustion quality. AlDurra A. et al [11], introduce a crank angle mathematical model for the combustion process involving the definition of a burn rate function. Linear parameter varying techniques are implemented in order to cover the total operating points and conditions in steady a and transient state. Syed Abbas Ali and Samir Saraswati [12], reconstruct the in-cylinder pressure and indicated torque of a diesel engine using crankshaft speed fluctuations with the implementation of frequency response functions. The relevant results demonstrate significant agreement between the estimated and the measured pressure data. Finally, Jairo A. Grajales et al [13], determine the incylinder pressure of a spark ignited engine by developing a polynomial mathematical model which combines acceleration signals from the head of the cylinder along with the average rotational speed per cycle calculated between vibration peaks.

In this paper the pressure of the cylinders of a diesel engine-synchronous generator set is being estimated by applying two methods. The first method considers the current and the speed of the synchronous generator in order to estimate the diesel engine developed torque, utilizing at the same the equations describing the dynamic model of the crankshaft, which lead to the estimation of the in-cylinder pressure. The second method aims to the development of a mathematical model, in a preliminary stage, which will relate acceleration signals directly to the developed in-cylinder pressure. This is pursuit since it would be more convenient and less cost demanding, the installation of the accelerators in comparison with the installation of speed encoders due to 
accessibility or sensitivity reasons. However, the method demands an existing timeseries pair of pressure and acceleration data, from a similar or identical diesel engine. This could be achieved either by deriving data directly from pressure sensors, or by the implementation of complex thermodynamic accompanied by mechanical mathematical models. In this case, there was an existing pair of pressure and acceleration data obtained in the past from now on called "original data". Two mathematical models relating acceleration to pressure are extracted based on this pair of data by applying system identification techniques. Then the in-cylinder pressure is estimated applying the extracted mathematical models to the acceleration signals obtained by the installed accelerometers on the top of the cylinders.

\section{Experimental test bench}

The experimental test bench is presented in Fig. 1. The electric power production set consists of a Lombardini 8LD 665-2 $21 \mathrm{~kW}$ diesel engine and a MECC-ALTE synchronous generator of $22 \mathrm{kVA}$ operating as 1-phase. The data with respect to diesel engine are given in Table 1 . The measurements which were performed comprise three types of sensors. Accelerometers placed on the top of the cylinders, current sensors and a speed sensor. The data acquisition system which has been developed for the collection and record of the relevant signals utilizes a PCI-1716 card. The measurement procedure considered several load conditions and tests. However, in this study the experiments were focused mainly on the start of the generator set and its settlement on a specific electric load. The placement of the accelerometers was chosen to be in vertical position due to the fact that the greatest correlation between vibration and cylinder pressure is when the accelerometers are in the vertical position, Jairo A. Grajales et al [13]. The experimental test bench is demonstrated in Fig. 1.

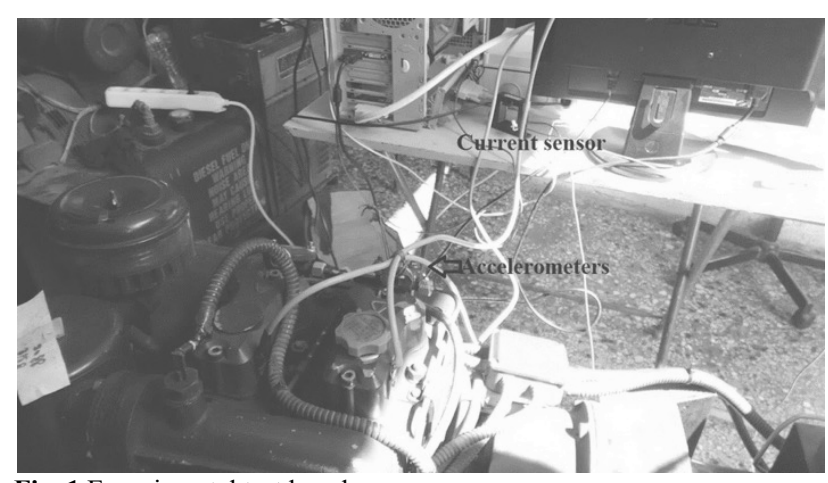

Fig. 1 Experimental test bench

\section{Applied analysis}

\section{$3.11^{\text {st }}$ Method. Implementation of crankshaft dynamic} model.

The calculation of the in-cylinder pressure of the diesel engine is based on two direct measurements by utilizing the crankshaft dynamic model as described by Li Zhixiong et al [14]. The two direct measurements are the current developed by the synchronous generator and the speed of the power generation set.

The crankshaft dynamic model as it is depicted by $\mathrm{Li}$ Zhixiong et al [14] is given by the following equation.
$J(\Theta) \ddot{\Theta}=T_{I}-T_{R}-T_{F}-T_{L}$

where $T_{I}$ is the indicated torque, $T_{R}$ is the torque due to the reciprocating masses, $T_{F}$ is the friction torque and $T_{L}$ is the load torque, which is actually the opposing counter torque induced by the synchronous generator. $\Theta$ is the angular position of the synchronous generator and diesel engine. The torque of the reciprocating masses $T_{R}$ is given by Eq. 2 as follows.

$\mathrm{T}_{\mathrm{R}}=\sum_{\mathrm{k}=1}^{\mathrm{N}} \mathrm{T}_{\mathrm{R}}^{\mathrm{k}}=\mathrm{m}_{1} \mathrm{R}^{2} \sum_{\mathrm{k}=1}^{\mathrm{N}}\left\{\left[\left(\ddot{\theta} \mathrm{f}\left(\theta-\varphi_{\mathrm{k}}\right)+\dot{\theta}^{2} \mathrm{~g}(\theta-\right.\right.\right.$ $\left.\left.\varphi_{\kappa}\right)\right] \mathrm{f}\left(\theta-\varphi_{\kappa}\right\}$

Where $f(\theta)$ and $g(\theta)$ are given in Eq. 3 and Eq. 4.

$f(\theta)=\sin \theta+\frac{\lambda \sin (2 \theta)}{2 \sqrt{1-\lambda^{2} \sin ^{2}(\theta)}}$

$g(\theta)=\cos \theta+\frac{\lambda \cos (2 \theta)}{2 \sqrt{1-\lambda^{2} \sin ^{2}(\theta)}}+\frac{\lambda^{3} \sin ^{2}(2 \theta)}{4 \sqrt{\left(1-\lambda^{2} \sin ^{2}(\theta)\right)^{3}}}$

where $\lambda$ is the connecting rod to crank radius ratio.

The term $\varphi_{\kappa}$ denotes the phase of the kth cylinder as given in Eq. 5

$\varphi_{\kappa}=\frac{4 \pi}{N}(\kappa-1)$

The total inertia $\mathrm{J}(\theta)$ varies according to the following formula

$J(\Theta)=m_{1} R^{2}\left(\sin \theta+\frac{\lambda \sin (2 \theta)}{2 \sqrt{1-\lambda^{2} \sin ^{2}(\theta)}}\right)^{2}+m_{2} R^{2}$

The friction torque is approximated by using the following equation:

$\mathrm{T}_{\mathrm{f}}=\mathrm{D} \dot{\theta}$

where $\mathrm{D}$ is the damping coefficient

The mechanical load imposed on the diesel engine by the synchronous generator as a counter torque is calculated by Paul C. Krause [15], I. Boldea, and S.A. Nasar [16], using the following equations:

$\mathrm{P}_{\mathrm{GEN}}=\frac{\mathrm{E}_{\mathrm{f}} \mathrm{V}_{\mathrm{T}}}{\mathrm{X}_{\mathrm{s}}} \sin \delta$

$\mathrm{E}_{\mathrm{f}}=\frac{\omega \mathrm{L}_{\mathrm{f}} \mathrm{I}_{\mathrm{f}}}{\sqrt{2}}$

$\mathrm{V}_{\mathrm{T}}=\mathrm{E}_{\mathrm{f}}-\left(\mathrm{R}_{\mathrm{s}}+\mathrm{jX} \mathrm{X}_{\mathrm{d}}\right) \mathrm{I}_{\mathrm{s}}+L_{\mathrm{s}} \frac{\mathrm{dI}_{\mathrm{s}}}{\mathrm{dt}}$

$\mathrm{T}_{\mathrm{L}}=\mathrm{T}_{\mathrm{GEN}}=\frac{\mathrm{P}_{\mathrm{GEN}}}{\omega_{\mathrm{GEN}}}$

Where $\mathrm{V}_{\mathrm{T}}$ is the terminal voltage, $\mathrm{E}_{\mathrm{f}}$ is the internal voltage developed due to excitation current, $\delta$ is the power angle, $\mathrm{P}_{\mathrm{GEN}}$ is the power produced by the generator, $\mathrm{I}_{\mathrm{f}}$ is the excitation current, $I_{s}$ is the measured current produced by the generator, and $\mathrm{R}_{\mathrm{s}}, \mathrm{L}_{\mathrm{s}}, \mathrm{X}_{\mathrm{d}}$, and $\mathrm{L}_{\mathrm{f}}$ are parameters associated with the circuits of the synchronous generator.

Finally, the indicated torque is a function of the contribution of each in-cylinder pressure $\mathrm{p}(\mathrm{k})$ and it is given 
in Eq. 12, where $\mathrm{B}$ is the bore of each cylinder. As it is obvious, the Eq. 12 has two unknown variables, i.e. the pressure $\mathrm{p}(\mathrm{k})$ in each cylinder. A solution to the problem is the calculation of a weight factor which relates the contribution of each cylinder torque to the total indicated torque of the engine, M.Kyunghan et al [17].

However, assuming equal angle-pressure relationship in all cylinders the solution of Eq. 12 with respect to in-cylinder pressure can be reduced to one variable equation.

$\mathrm{T}_{\mathrm{i}}=\sum_{\mathrm{k}=1}^{\mathrm{N}} \mathrm{T}_{\mathrm{i}}^{\mathrm{k}}=\frac{\pi \mathrm{B}^{2}}{4} \mathrm{R} \sum_{\mathrm{k}=1}^{\mathrm{N}}\left[\mathrm{p}(\mathrm{k}) \mathrm{f}\left(\theta-\varphi_{\mathrm{\kappa})}\right]\right.$

Combining the above equations and the relevant recorded measurements for current and speed, the in-cylinder pressure of each cylinder is obtained.

\section{2 $2^{\text {nd }}$ Method. Implementation of system identification techniques.}

System Identification techniques utilize statistical methods to determine mathematical models of dynamical systems from existing time series data with respect to input(s) and output(s) of the examined system G. Box and G. Jenkins [18], L. Ljung [19], T. Soderstrom. and P. Stoica [20].

System identification techniques relate input(s) and output(s) in the form of differences equations, i.e in discrete time domain. Two of the most characteristic models which are being involved in various scientific areas like systems modeling, control, processes e.t.c., are the ARX and ARMAX models.

The general equation of differences which describe an ARX model is:

$$
y(t)+a_{1} y(t-1)+\cdots+a_{n a} y(t-n a)=b u(t-1)+
$$$$
\cdots+b_{n b}(t-n b)+e(t)
$$

Where $u(t), u(t-1), \ldots, u(t-n a)$ are the input time series data, and $\mathrm{y}(\mathrm{t}), \mathrm{y}(\mathrm{t}-1), \ldots, \mathrm{y}(\mathrm{t}-\mathrm{nb})$ are the output time series data. The $\mathrm{e}(\mathrm{t})$ is the term of the error or the 'white noise'. The maximum delay in both input and output series data is determined by the order of the ARX model.

Similarly, the equation of differences describing an ARMAX model is given by:

$$
\begin{aligned}
& y(t)+a_{1} y(t-1)+\cdots+a_{n a} y(t-n a)=b_{o} u(t-d)+ \\
& b_{n b} u\left(t-d-n_{b)}+e(t)+c_{1} e(t-1)+\cdots+c_{n c} e\left(t-n_{c}\right)\right.
\end{aligned}
$$

The distinction between an ARX and an ARMAX model is the existence of the error terms in the equation of differences of the ARMAX model.

Several methods are implemented for the determination of the parameters of the ARX and ARMAX model. A common one for both models is the development of the following expression Eq. (15), the determination of its derivative and the set of the derivative equal to zero. $\Phi(\mathrm{t})$ is the vector of the input(s) and output(s) time series data at specific time observations (delays). $\Theta$ is the vector of the coefficients of the equation of differences which have to be determined. This method is also called the "least squares" method.

$$
V=\frac{1}{N} \sum_{N=1}^{N}\left(y(t)-\Phi^{T}(t) \Theta\right)^{2}
$$

Other methods for the determination of the parameters of an ARMAX model are the "Recursive Least Square
Estimation" and the Forgetting factor. The first one aims towards the minimization of the computing burden. The second one aims towards the minimization of the samples of the time series used in order to stress on the dynamical behavior of the examined system without at the same time the development of infinites in the calculations.

The general methodology for extracting a dynamical model for an examined system is summarized in the following steps.

$>$ Filtering the time series data in frequency intervals related to the operation frequencies of the examined system.

$>$ Time series chopping in smaller intervals (parts) and examination of the resulting models.

Adoption of the model with the best fit (minimum divergence) concerning the entire signal.

$>$ Examination of the frequency response of the adopted dynamical model.

\section{Results and Discussion}

4.1 $1^{\text {st }}$ case. Estimation of the in-cylinder pressure by considering the dynamic crankshaft model

In the first case the diesel engine-synchronous generator set starts from cold and settles to an operating point which corresponds to $8.1 \mathrm{~kW}$ electric load. The relevant figures which demonstrate the variation of current as recorded by the current sensor, its estimated true rms value and the recorded speed of the diesel engine-synchronous generator set are shown in Figs. 2 to 4 respectively. The variation of the estimated torque which corresponds to the operating point of $8.1 \mathrm{~kW}$ is shown in Fig. 5.

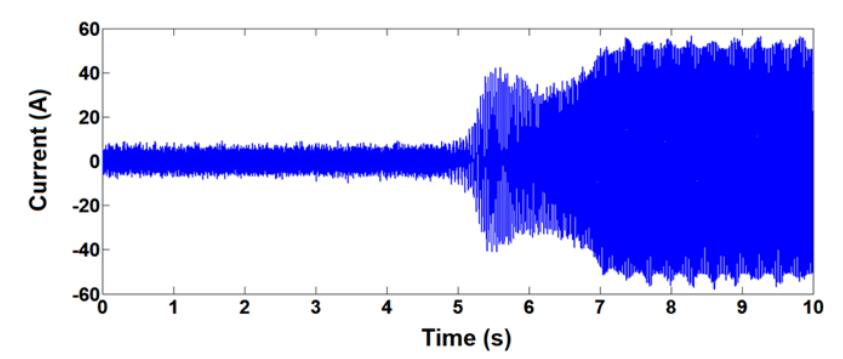

Fig. 2 Instantaneous current of synchronous generator

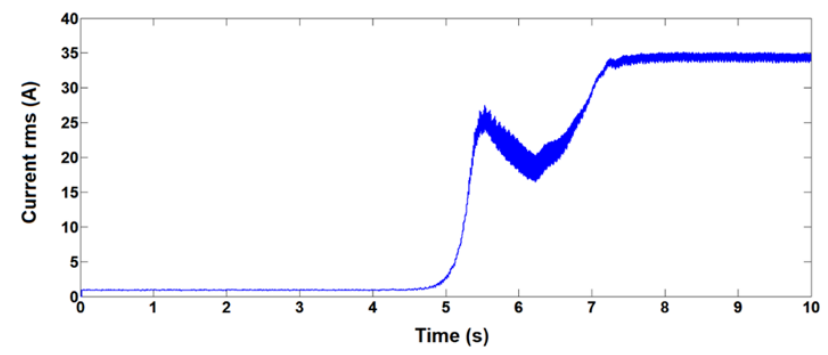

Fig. 3 Current of the synchronous generator (true rms values)

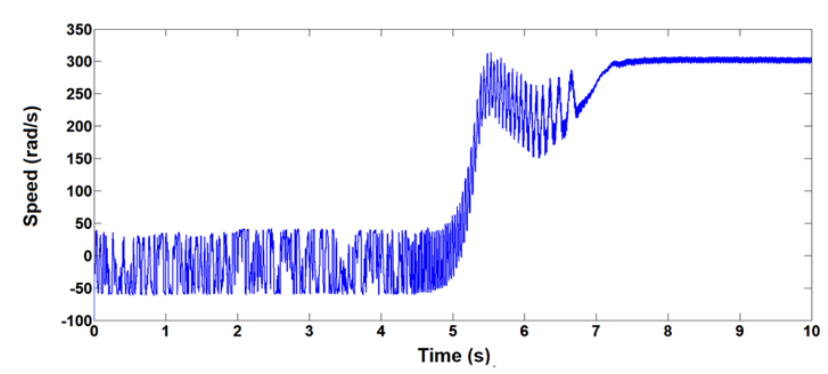

Fig. 4 Speed of diesel engine-synchronous generator set 


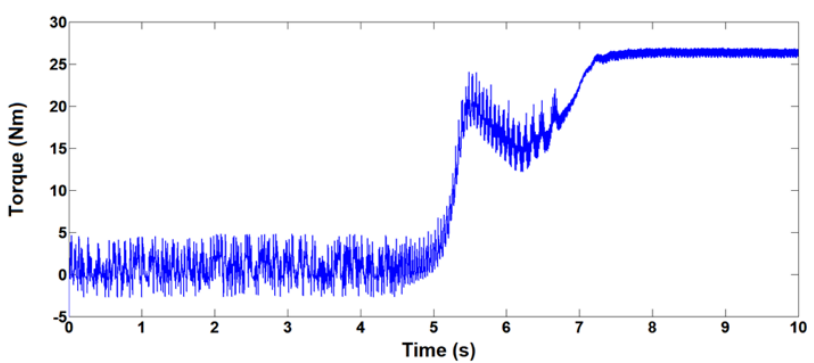

Fig. 5 Torque developed by the synchronous generator

The output voltage of the synchronous generator was regulated to be $231 \mathrm{~V}$. The synchronous generator acts as a mechanical load to the diesel engine, developing a countertorque imposed on the diesel engine. The torque of the diesel engine-synchronous generator set is $27 \mathrm{Nm}$ at steady state. The speed at steady state is approximately $307 \mathrm{rad} / \mathrm{sec}$, i.e. $2933 \mathrm{rpm}$. This means that he rotation frequency is $48.883 \mathrm{~Hz}$ and the frequency of the four-stroke cycle is $24.44 \mathrm{~Hz}$ since it takes two revolutions to be completed. In time domain this corresponds to a time interval of 0.0409 seconds. The relevant results which show the variation of the in-cylinder pressure with time when the system is settled to its operating point are demonstrated in Figs. 6 and 7 respectively.

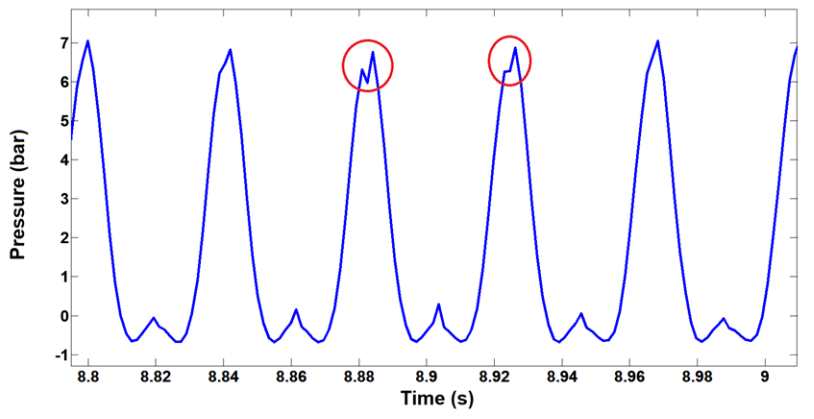

Fig. 6 Estimated in cylinder pressure of diesel engine

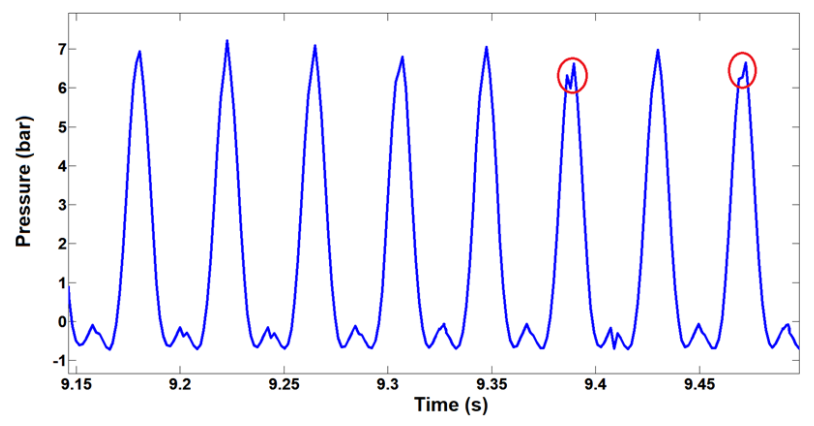

Fig. 7 Estimated in cylinder pressure of diesel engine

The red marks at the top of several points indicate combustion delay. Since, there were no direct measurements of the in-cylinder pressure of the specific operated diesel engine, an indirect method was followed to validate the relevant results. This was accomplished by the calculation of the average in-cylinder pressure per cycle and the comparison with the mean effective pressure given by the following formula.

$\mathrm{T}=\frac{\mathrm{P}_{\mathrm{me}} \mathrm{V}_{\mathrm{d}}}{2 \pi \mathrm{n}_{\mathrm{r}}}$
The Eq. 15, relates the developed torque of a diesel engine with its mean effective pressure $\left(P_{m e}\right)$, where $V_{d}$ is the engine displacement and $n_{r}$ corresponds to 2 for a four-stroke engine. The mean effective pressure for the total developed torque of $27 \mathrm{Nm}$ was found to be 2.545 bar for each cylinder, whereas the average pressure value in each complete four-stroke cycle was found to be 2.62 bar.

\section{$4.22^{\text {nd }}$ case. Estimation of the in-cylinder pressure by} implementing system identification Techniques

As it has already been discussed in the introduction section, this method of relating acceleration data directly to pressure data is based on an existing pair of data (original data) obtained in the past from an identical diesel engine. The speed of the identical diesel engine during operation was about 2866 rpm. This means that the characteristic frequencies like combustion frequency and the valve seating for each cylinder are $23.88 \mathrm{~Hz}$, and $47.76 \mathrm{~Hz}$ respectively. Also, the frequency of the piston side thrust impact is expected to be at $95.52 \mathrm{~Hz}$ by assuming 4-point contact of the piston with the cylinder bore. A small portion of the original data is demonstrated in Fig. 8, after processing it in a low frequency band which contains the above-mentioned frequencies.

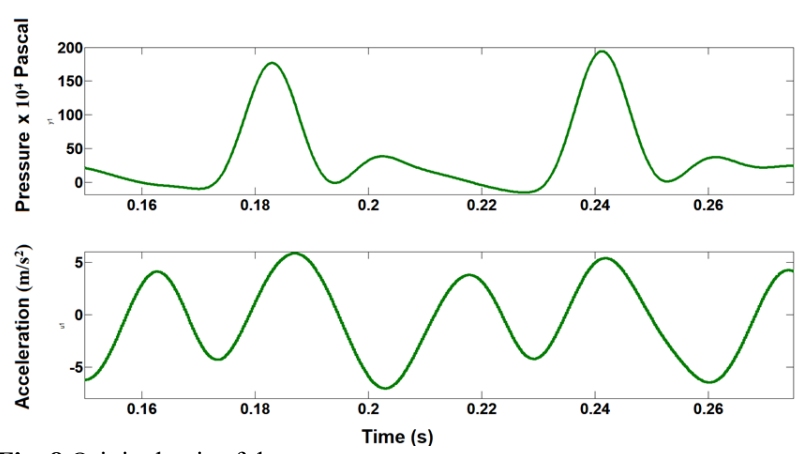

Fig. 8 Original pair of data

The procedure as discussed above in section 3.2 was implemented on the original pair of data in order to estimate suitable mathematical models relating acceleration directly to in-cylinder pressure. Several tests were performed with ARX and ARMAX models of different orders, however the most suitable one proved to be the ARMAX 4441.

Two ARMAX 4441 models were identified. The first one is given below after its conversion from the domain of discrete time to the domain of continuous time is given by the following equation.

$H(s)=\frac{-5630.4 s^{3}+3.53782 e^{2} s^{2}+1.2078 \mathrm{e} 8 \mathrm{~s}+1.139 \mathrm{e} 11}{1 \mathrm{~s}^{4}+195.255 \mathrm{~s}^{3}+1.6765 \mathrm{e}^{2} \mathrm{~s}^{2}+5.1769375 \mathrm{e} 6 \mathrm{~s}+3.185 \mathrm{e} 09}$

The obtained in-cylinder pressure by implementing the above transfer function on the original acceleration data is compared to the original (measured) in-cylinder pressure, as it is demonstrated in Fig. 9. The relevant results are compared to a portion of the total combustion cycle which comprises the compression, the expansion and the exhaust. The evaluation of the extracted ARMAX models was evaluated by calculating Mean Squared Error which was found to be 0.002893 .

The frequency response of the above transfer function $\left(1^{\text {st }}\right.$ ARMAX model) is demonstrated in Fig. 10, where the expected characteristic frequencies of the operating point of the original data are identified. 


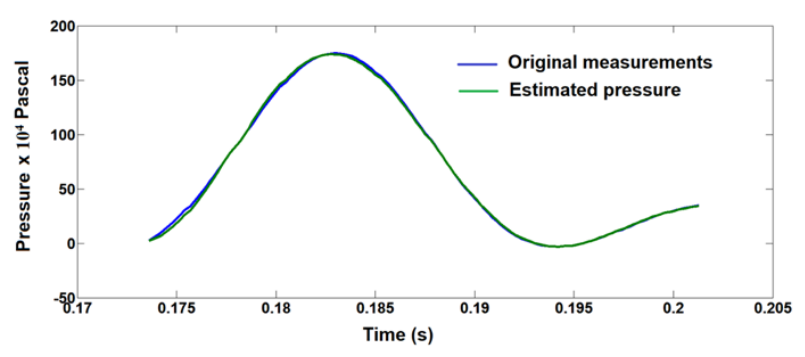

Fig. 9 Comparison between the measured in-cylinder pressure of the original pair of data and the estimated from the $1^{\text {st }}$ ARMAX model

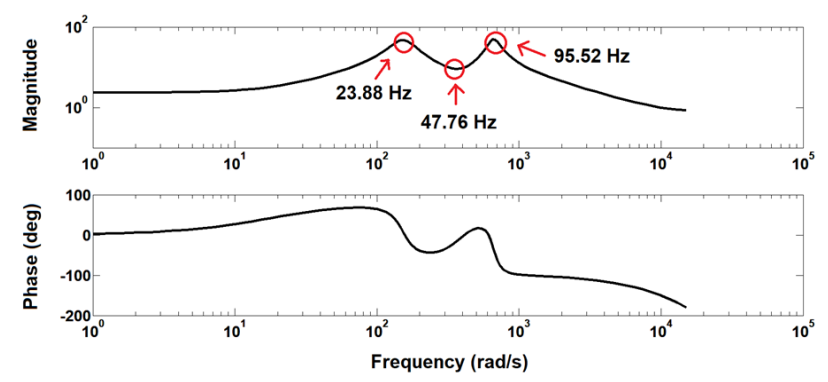

Fig. 10 Frequency response diagram of the $1^{\text {st }}$ ARMAX model

Then, the in-cylinder pressure of the diesel engine of the experimental test bench was obtained for the same scenario of section 4.1, by using the Eq (16) and the acceleration data as they are given in Fig. 11 after being processed to a lower frequency band. The relevant results are demonstrated in comparison to the results of the crankshaft dynamic model in Fig. 12.

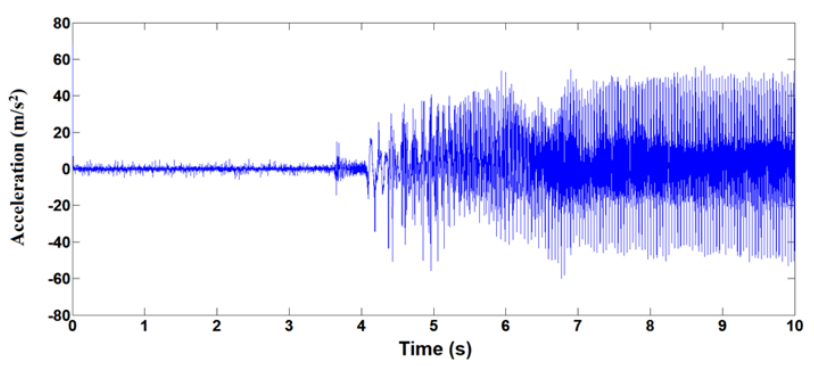

Fig. 11 Acceleration data from the operating diesel-engine

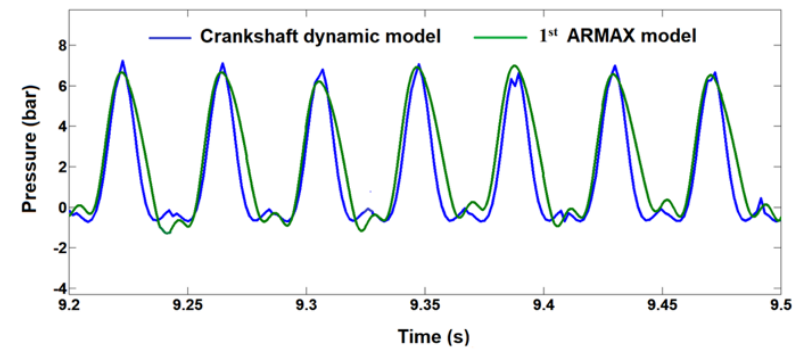

Fig. 12 Estimated in-cylinder pressure. $1^{\text {st }}$ ARMAX model in comparison to first method.

A second ARMAX model was identified by focusing only to compression and expansion. The transfer function corresponding to this model is:
$H(s)=\frac{-6294 s^{3}+2.662 e 5 s^{2}+6.156 e 8 s+8.646 e 08}{1 s^{4}+342.4 s^{3}+1.998 e 5 s^{2}+1.078 e 7 s+4.367 e 09}$

The relevant results in compared to the results from the implementation of the crankshaft dynamic model are given in Fig. 13.

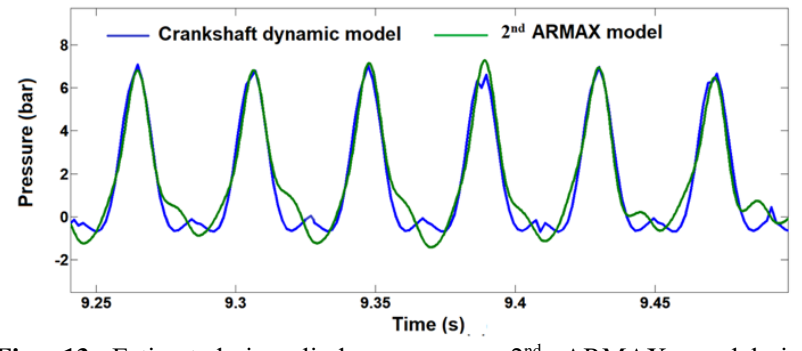

Fig. 13 Estimated in-cylinder pressure. $2^{\text {nd }}$ ARMAX model in comparison to first method.

As it is obvious the results obtained for the in-cylinder pressure, derived from the implementation of the $1^{\text {st }}$ ARMAX model have a greater resemblance to that obtained by the implementation of the crankshaft dynamic model particularly in the region of intake, compression and exhaust. As for the case of the results obtained from the implementation of the $2^{\text {nd }}$ ARMAX model demonstrate a great coincidence in the region of compression and expansion with the results obtained from the implementation of the crankshaft dynamic model, as it was expected to be. A diversification between the two methods is the detection of the combustion delay only in the first method. An optimization of the algorithm which calculates the ARMAX method in several regions of the combustion problem will alleviate the problem and improve the sensitivity to the detection of possible faults.

\section{Conclusions}

The in-cylinder pressure of a diesel engine-synchronous generator set is estimated by following two approaches. The first one deals with the application of a mathematical model considering the dynamics of the crank shaft system, and the synchronous generator. The relevant results are compatible with the existing experience in the field. The second one deals with the implementation of system identification techniques in order to relate directly acceleration data to the in-cylinder pressure. The relevant results are very promising and in the future an optimization technique will be implemented in order to improve the procedure and to ensure reliability for the whole region of the combustion process. Several experiments will be carried out with the application of several faults like valves clearance, piston slaps e.t.c., in order to improve the sensitivity of the identified models to the possible faults.

This is an Open Access article distributed under the terms of the Creative Commons Attribution License

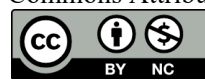

\section{References}

[1] Hubbard M, Dobson PD and Powell JD (1976) Closed loop control of spark advance using a cylinder pressure sensor. Transaction of the ASME, Journal of Dynamic Systems, Measurement, and Control 98(4): 414-420.
[2] Morris J and Li-Chi (1985) Improved intra-cylinder combustion pressure sensor. SAE Technical Paper 850374: 137-146.

[3] Winter H, Mock R and Meixner H (1988) A high temperature pressure sensor for the combustion chamber of spark ignition engines. 
Proceedings of the 18th International Symposium Automotive Technology, p. 2.

[4] Chandroth G. O., Sharkey A. J. C., Sharkey N. E. Cylinder pressures and vibration in internal combustion engine condition monitoring. Proceedings of Comadem 99, 1999.

[5] d'Ambrosio S., Ferrari A., Galleani L. n-cylinder pressure-based direct techniques and time frequency analysis for combustion diagnostics in IC engines. Energy Conversion and Management, Vol. 99, 2015, p. 299-312.

[6] Brown TS and Neill WS (1992) Determination of engine cylinder pressures from crankshaft speed fluctuations. SAE Technical Paper 920463: 771-779.

[7] P. F. Maria, S. Santini and P. Langthaler, "Torque generation model for Diesel Engine", Proceedings of the $42^{\text {nd }}$ IEEE Conference on Decision and Control. Maui, Hawaii USA, Dec. 2003.

[8] Citron SJ, O'Higgins JE and Chen L (1989) Cylinder by cylinder engine pressure and pressure torque waveform determination utilizing speed fluctuations. SAE Technical Paper 890486: 933-947.

[9] Schagerberg S and McKelvey T (2003) Instantaneous crankshaft torque measurements - modeling and validation. SAE Technical Paper 2003-01-0713.

[10] Taglialatela F., Lavorgna M., Mancaruso E., Vaglieco B. M. Determination of combustion parameters using engine crankshaft speed. Mechanical Systems and Signal Processing, Vol. 38, Issue 2, 2013, p. 628-633.

[11] Al-Durra A., Canova M., Yurkovich S. A real-time pressure estimation algorithm for closed-loop combustion control.
Mechanical Systems and Signal Processing, Vol. 38, 2013, p. 411427.

[12] Syed Abbas Ali, Samir Saraswati, "Cycle-by-cycle estimation of cylinder pressure and indicated torque waveform using crankshaft speed fluctuations", Transactions of the Institute of Measurement and Control 2015, Vol. 37(6) 813-825.

[13] Jairo A. Grajales, Héctor F. Quintero, Carlos A. Romero, Edison Henao, Juan F. López, Daniela Torres, "Combustion pressure estimation method of a spark ignited combustion engine based on vibration signal processing", Journal of Vibroengineering, Nov 2016, Vol. 18, Issue 7, pp. 4236-4247.

[14] Li Zhixiong, Guo Zhiwei, Hu Chongqing, Li Aihua, "On-line indicated torque estimation for internal combustion engines using discrete observer", Computers and Electrical Engineering, Vol 60, 2017, pp. 100-115.

[15] Paul C. Krause, "Analysis of Electric Machinery", McGraw-Hill International Editions, New York, 1987.

[16] I. Boldea, S.A. Nasar, "Electric Machine Dynamics", Macmillan Publishing Company, New York, 1986.

[17] M.Kyunghan, C.Jaesung, K.Eunhwan, andS.Myoungho. Individual cylinder imep estimation using a single cylinder pressure sensor for light-duty diesel engines. SAE Technical Paper 2014-01-1347, 2014.

[18] G. Box and G. Jenkins. Time Series Analysis: Forecasting and Control . Prentice-Hall, 1987.

[19] L. Ljung. System Identification, Theory for the User. Prentice Hall, 1987.

[20] T. Soderstrom. and P. Stoica. System Identification. Prentice-Hall Engle 